\title{
Compromise between environmental burdens and performance in strengthening steels
}

\author{
Noriyuki TSUCHIDA \\ Domestic Research Fellow, Japan Science and Technology Corporation, 1-2-1, Sengen, Tsukuba, \\ Ibaraki 305-0047, Japan \\ TEL: +81-298-59-2290 FAX:+81-298-59-2201 e-mail:TSUCHIDA.Noriyuki@nims.go.jp \\ Kotobu NAGAI \\ Materials Engineering Laboratory, National Institute for Materials Science, 1-2-1, Sengen, \\ Tsukuba, Ibaraki 305-0047, Japan \\ TEL: +81-298-59-2240 FAX:+81-298-59-2201 e-mail: NAGAI.Kotobu@nims.go.jp \\ Yo TOMOTA \\ Faculty of Engineering, Ibaraki University, 4-12-1, Nakanarusawa, Hitachi, Ibaraki, 316-8511, \\ Japan \\ TEL: +81-294-38-5055 FAX: +81-294-38-5226 e-mail: tomota@ipc.ibaraki.ac.jp \\ (Received 1, October 2001 Accepted 7, December 2001)
}

\begin{abstract}
In order to develop the steels bearing low environmental burdens as well as high performances, the present situation in Japan has been analyzed from several points of view. The issues related with steel production include 1) potentiality of the domestic contribution to reducing the global amount of $\mathrm{CO}_{2}$ emission and 2) possible recipes in practical process to lower the environmental load with high performance. A sector occupying a huge share in the industry field can reduce the $\mathrm{CO}_{2}$ emission effectively and the steel industry is such the sector. A sophisticated use of thermo-mechanical process in steel production can improve both the environmental and the service performance. By lowering the heating temperature in the thermo-mechanical process, the $\mathrm{CO}_{2}$ emission can be decreased and the yield strength can be increased by ultrafine-grain strengthening.
\end{abstract}

Keywords: Yield strength, $\mathrm{CO}_{2}$ emission, Ultrafine grain strengthening, Solid solution hardening, Precipitation hardening

\section{INTRODUCTION}

Steel has been manufactured approximately 100 Mt in Japan every year which occupies about $46 \%$ in the total amount of materials manufactured in Japan. The amount of $\mathrm{CO}_{2}$ emission in Japan occupies about $5 \%$ of the global amount. ${ }^{1}$ In Japan the $\mathrm{CO}_{2}$ emission in the steel industry occupies about $34 \%$ in the category of industry. ${ }^{2,3}$
That is about $13 \%$ of the domestic total amount. Figure 1. shows a change in curtailment rate of $\mathrm{CO}_{2}$ emission in Japan for the steel industry, chemical industry and construction industry, respectively. Hence, $10 \%$ curtailment in the steel industry can reduce about $1 \%$ of the total $\mathrm{CO}_{2}$ emission in Japan. By considering steel scrap increasing and steel recycling, the future role of steel in the 
resources-circulating society will become more important.

In this study, a balance between the amount of $\mathrm{CO}_{2}$ emission during the production and the yield strength is investigated for several strengthening mechanisms to propose the steels showing both low environmental burdens and high performances. Here, solid solution hardening, precipitation hardening and ultrafine grain strengthening are selected as the strengthening mechanisms

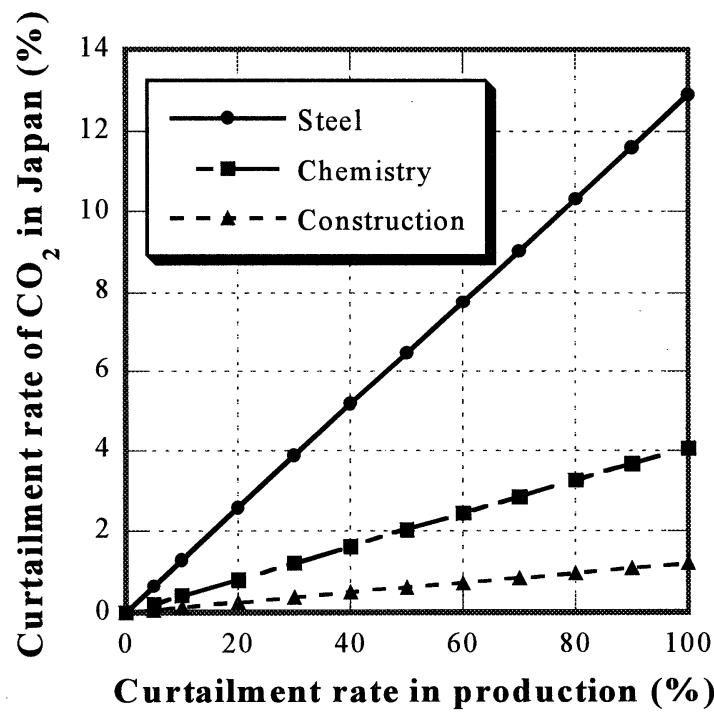

Fig. 1. Effects of the category of industry on curtailment rate of $\mathrm{CO}_{2}$ emission in Japan.

\section{PROCEDURE}

The MLCA database developed by Halada et al. ${ }^{4}$ is used to evaluate the environmental loads in terms of $\mathrm{CO}_{2}$ emission in the production of hot strip slab.

The database including unit requirements of fuel and electric power for furnace and hot strip mill is referred to the data from Japanese steel industries. ${ }^{5,6}$ Here, based on the variations of unit requirements of fuel and electric power from 1970's and 1980's and the relationship between unit requirement of fuel and inserting temperature of slab, their unit requirements in thermo-mechanical process were determined according to heating temperatures and deforming temperatures. Figures 2 and 3 show unit requirement of fuel for furnace and hot strip mill as a function of inserting temperature of slab, respectively. The unit requirement of fuel at heating and deforming temperatures can be estimated for calculations of $\mathrm{CO}_{2}$ emission.

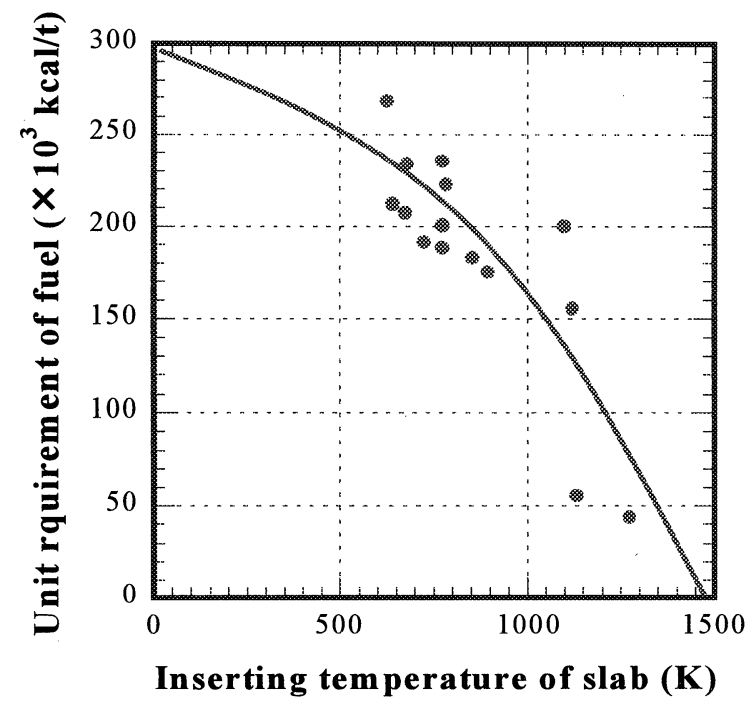

Fig. 2. Unit requirement of fuel for heating furnace as a function of inserting temperature of slab. ${ }^{5}$

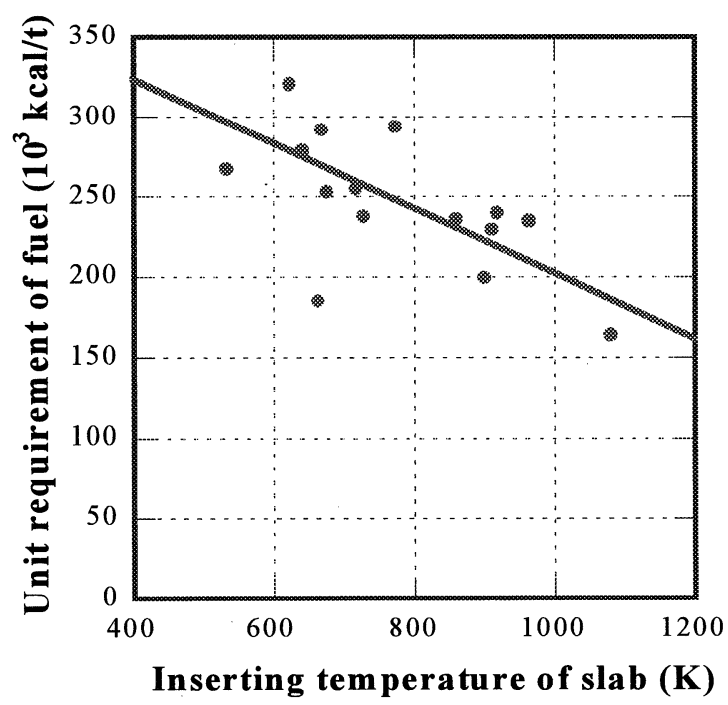

Fig. 3. Unit requirement of fuel for rolling as a function of inserting temperature of slab. ${ }^{5}$

The following equation summarized by Pickering ${ }^{7}$ is used to calculate the yield strength (YS) of ferrite-pearlite steels for various alloying elements and ferrite grain sizes. 
YS [MPa]

$=15.4\left[3.5+2.1(\mathrm{Mn})+5.4(\mathrm{Si})+23\left(\mathrm{~N}_{\mathrm{f}}\right)+1.13 \mathrm{D}_{\alpha}^{-0.5}\right](1)$

where $\mathrm{Mn}, \mathrm{Si}, \mathrm{N}_{\mathrm{f}}$ and $\mathrm{D}_{\alpha}$ refer to $\mathrm{Mn}$ consentration in mass percent, $\mathrm{Si}$ one, free nitrogen one and ferrite grain size, respectively.

\section{RESULTS AND DISCUSSIONS}

Figure 4 shows the relationship between $\mathrm{CO}_{2}$ emission in the production and the yield strength for three strengthening mechanisms.

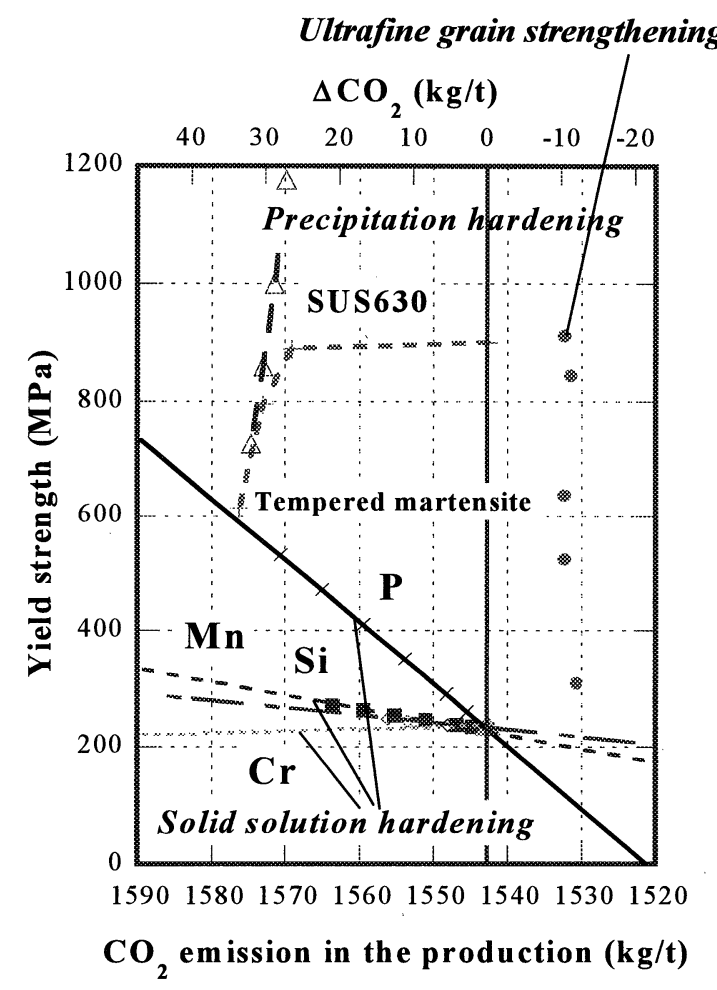

Fig. 4. Yield strength vs. $\mathrm{CO}_{2}$ emission in the production for three strengthening mechanisms.

\section{Reference material}

JIS-SM490 steel with a ferrite-pearlite structure is selected as reference material to compare three strengthening mechanisms. The $\mathrm{CO}_{2}$ emission and the yield strength of the reference material are as follows;

$\mathrm{CO}_{2}$ emission: $1542.7 \mathrm{~kg} / \mathrm{t}$,

Yield strength: $235 \mathrm{MPa}$.

\section{Solid solution hardening}

Figure 5 shows changes of $\mathrm{CO}_{2}$ emission by alloying elements. The MLCA database considers effects of alloying elements as the environmental load discharged in the productions of ferro-alloys. Figure 6 shows changes of yield strength by alloying elements. The yield strength increases with increasing the alloying elements except $\mathrm{Cr}$. Solid solution hardening thereby increases both the yield strength and the $\mathrm{CO}_{2}$ emission with increasing the alloying elements in most cases.

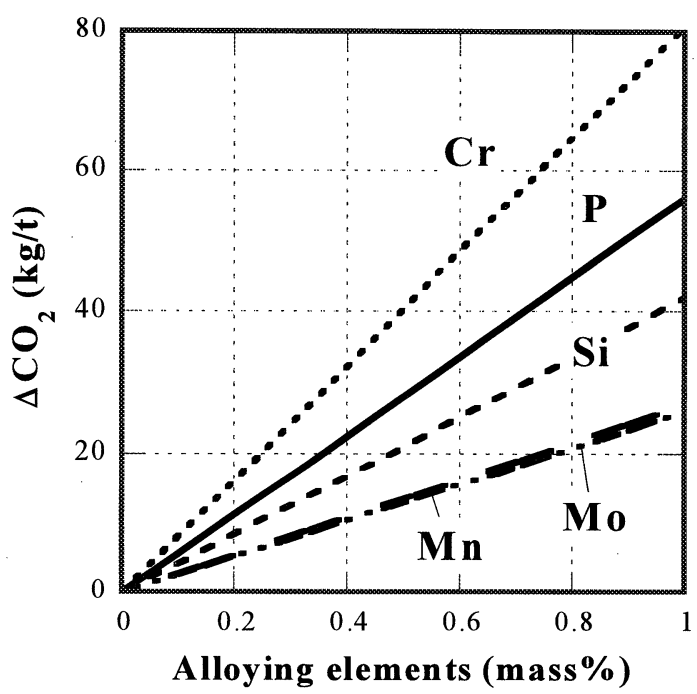

Fig. 5. Change of $\mathrm{CO}_{2}$ emission as a function of alloying elements. ${ }^{4}$

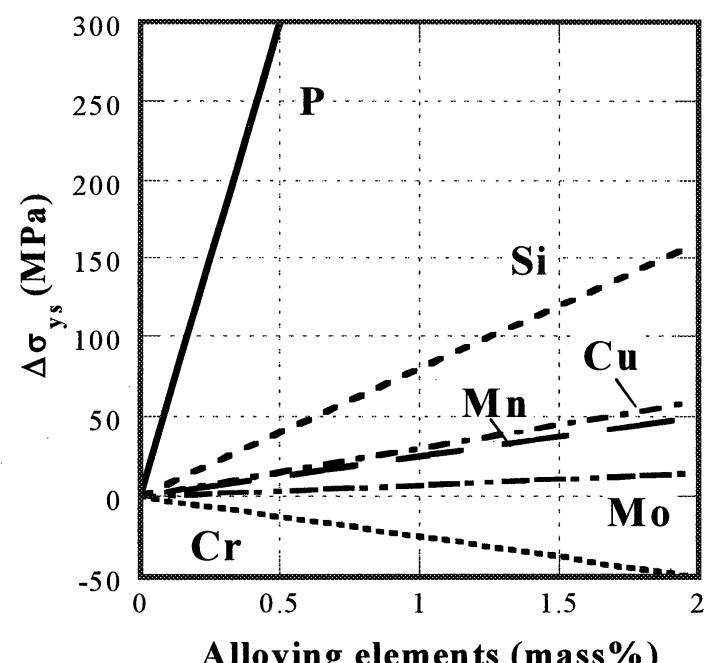

Fig. 6. Change of the yield strength as a function of concentrations of alloying elements.

\section{Precipitation hardening}

The balances for a tempered martensite steel and 
JIS-SUS630 are estimated. Figure 2 is used in order to estimate the change in the amount of $\mathrm{CO}_{2}$ emission by tempering while the yield strength is determined by experiments. The yield strength is decreased while the amount of $\mathrm{CO}_{2}$ emission is increased with increasing of tempering temperature.

\section{Ultrafine grain strengthening}

Ohmori et al. ${ }^{8}$ reported that ultrafine-grained steels with ferrite grain size between 0.5 and $2 \mu \mathrm{m}$ were obtained by changing the deforming temperature between 673 and $923 \mathrm{~K}$. In this experiment, rods were subjected to the multi-pass warm rolling with an accumulated area reduction of $93 \%$.

The yield strength increases with lowering the processing temperature by ultrafine grain strengthening. ${ }^{8}$ The unit requirement of fuel for furnace decreases with lowering heating temperature but that for hot strip mill increases with lowering deforming temperature as seen in Figs. 2 and 3. The $\mathrm{CO}_{2}$ emission increases with lowering those temperatures in the case of ultrafine grain strengthening.

The heating temperature of furnace and the deforming temperature of hot strip mill are major factors to affect the amount of $\mathrm{CO}_{2}$ emission in the thermo-mechanical process. The emission is suppressed by lowering those temperatures compared with that of reference material. Accordingly, the low temperature may decrease the $\mathrm{CO}_{2}$ emission and increase the strength.

\section{SUMMARY}

A balance between $\mathrm{CO}_{2}$ emission in the production and yield strength are estimated for three strengthening mechanisms. Low temperature process like ultrafine grain strengthening has a possibility to improve both the environmental loads and performance compared with the conventional process.

\section{REFERENCES}

${ }^{1}$ Quality of the Environment in Japan, (1999), Ministry of the Environment.

${ }^{2}$ Investigated report of Ministry of the Environment, (2001), Ministry of the Environment.

3 The Steel Industry of Japan 2001, (2001), The Japan Iron and Steel Federation.

${ }^{4}$ K.Halada: Proc. Int. Conference on EcoBalance, Tsukuba (1994), 288.

${ }^{5}$ Advanced Technology of Hot Strip Mill in Japan (1987), ISIJ.

${ }^{6}$ Advanced Technology of Plate Production in Japan (1984), ISIJ.

${ }^{7}$ F.B.Pickering and T.Gladman: Iron and Steel Inst. Spec. Rep., No. 81 (1963), 10.

${ }^{8}$ A.Ohmori, S.Torizuka and K.Nagai: CAMP-ISIJ, 14 (2001), 1128.

Presented at the $5^{\text {th }}$ International Conference on ECOMATERIALS Oct. 2-4, 2001,Honolulu, Hawai 